\title{
TORQUE DIAGRAMS FOR INTERNAL COMBUSTION ENGINES.
}

\author{
By A. T. J. KERSEY, A.R.C.Sc., Wr. Kx. \\ (MTMBER).
}

\section{Rúsumé.*}

The author had investigated three different types of engines: (a) Low-compression gas or petrol engine, mean effective pressure 80 lb. per sq. in. (b) High-compression engine, Otto cycle, mean effective pressure $125 \mathrm{lb}$. per sq. in. (c) High-compression engine, Diesel cycle, mean effective pressure $100 \mathrm{lb}$. per sq. in. Torque diagrams were constructed for speeds of $300,1,000,1,500$ and 2,000 revs. per minute, the result showing that the effect of inertia in modifying the shape of the torque diagram was small at comparatively low speeds, but very marked at the higher speeds.

Cylinder sizes were chosen so that the three types of engine selected gave approximately equal mean torques, i.e., approximately the same horse-power at any given speed. (The resulting torque curves at a speed of 300 revs. per minute are shown in Fig. 2, and at 2,000 revs. per minute in Fig. 3.) From Fig. 2 the author deduced that for the same mean torque the Diesel engine gave 40 per cent higher maximum torque than either of the other two. Comparison between Figs. 2 and 3 showed that the effect of inertia at the increased speed was to flatten out the peak of the diagram and reduce the maximum torque, the maximum negative torque being at the same time increased. Methods were outlined of allowing for varying weights of reciprocating parts and for reduced mean effective pressures at high speeds by the use of "corresponding" speeds. The author then went on to state that assuming a constant stroke/bore ratio, the high-compression engine, with its higher mean effective pressure, would have an advantage over the low-compression engine in respect of its reduction of total weight per given horse-power, and its smaller inertia torque at any given speed. He added that in this case at the same revolution speed the inertia torque would be inversely proportional to (M.E.P.). This again would place the Diesel engine at a dis-

* The complete paper in MS. form may be obtained on loan from the Library. 
advantage for high speeds. The author drew the attention of the members to the fact that there was no appreciable difference in the shapes of the torque diagrams of each type in Figs. 2 and 3.

In discussing the effects of periodic variations of nett torque from mean torque, he said that it would result in variation of pressure between the teeth of the pinion and the crown wheel in the final drive through the propeller shaft. He further stated that if torque variations were taken into acoount, complete balancing of the engine in any of the cases considered would not be possible even with a crankshaft of infinite stiffness. The author then gave in tabular form the range of torque, the energy stored in the flywheel from minimum to maximum speed, and a number of other particulars from various types of engine, from single-cylinder to six-cylinder vertical type, and Vee type engines arranged at various angles, and setting these out in ordier of merit on the basis of maximum nett torque per cylinder, he stated that the Vee type at 45 degrees with 6 cranks at 120 degrees would give the best results, as shown in Fig. 21. This Table also showed that the nett maximum torque was not greatly affected by increase of speed within the limits investigated, i.e., 2,000 revs. per minute.

The paper was illustrated by 23 diagrams, a fow typical ones of which are reproduced. There were also five Appendices as follows:-

Appendix A.-Expressions for inertia torque for engines with different cylinder arrangements.

APPEndix B.-Similar expressions for Vee type engines with various crank arrangements.

ApPendix C.-Expressions for the unbalanced vertical and horizontal forces, due to inertia, for each of the types dealt with.

APPENDIX D. - The effect of periodic variations of engine torque on the propeller shaft.

APPENDIX E.-The natural period of torsional vibration of the front end of the chassis due to periodic rariation of torque.

APPENDIX F. - Speed variation of engine due to varying torque. 
TORQUR DIAGRAMS FOR INTERNAL COMBUSTION HNGINES. 487

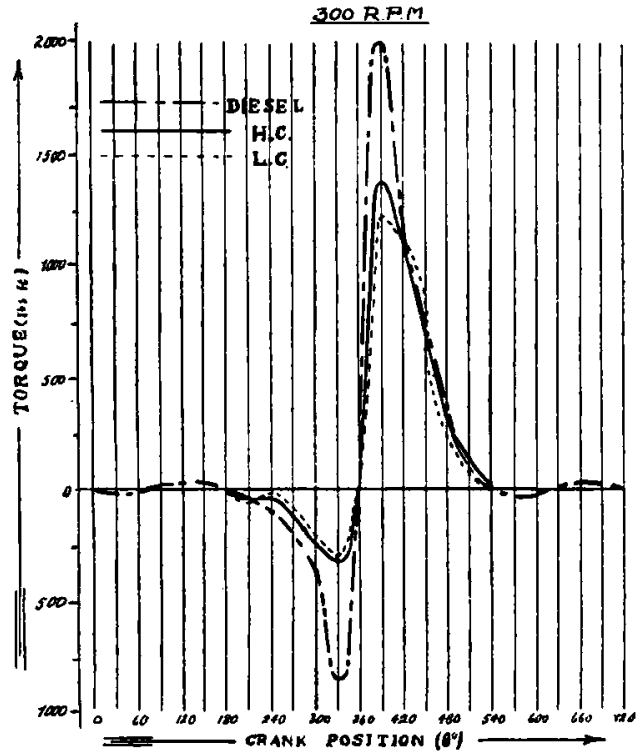

Fig. 2

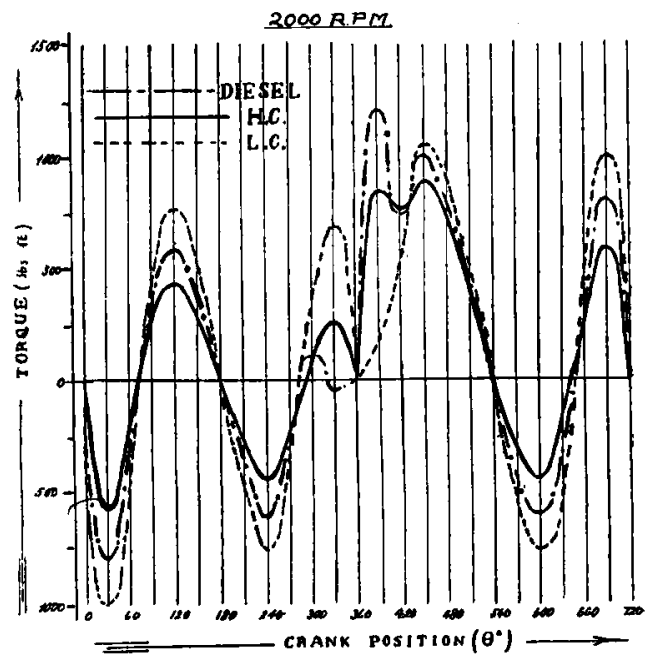

Fig. 3 


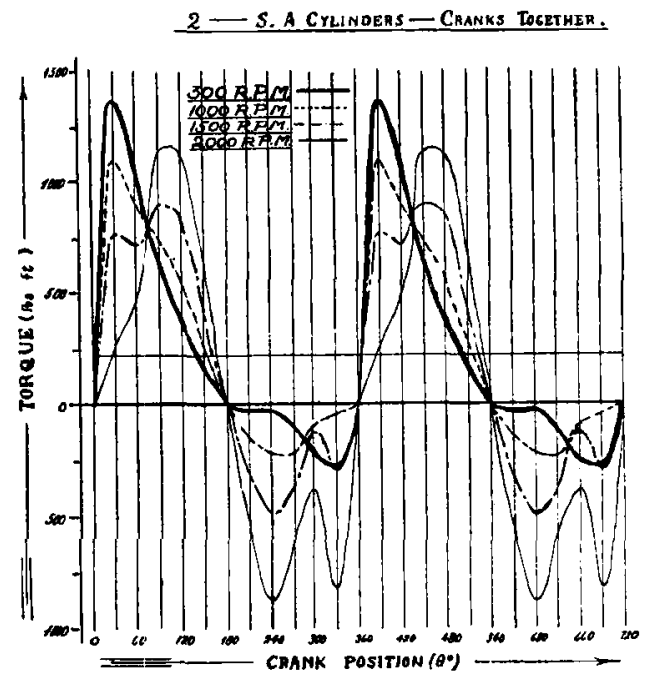

Fig. 7

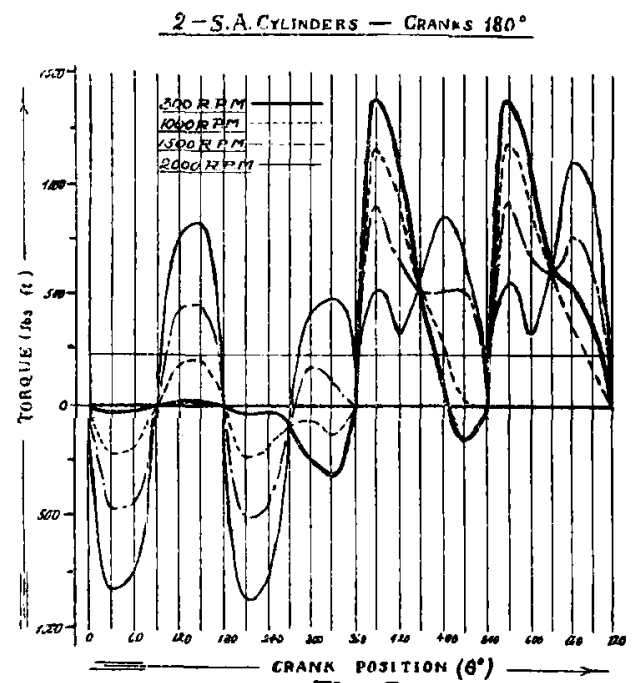

Fig. 8 
TORQUE DIAGRAMS FOR INTERNAL COMBUSTION RNGINES. 489

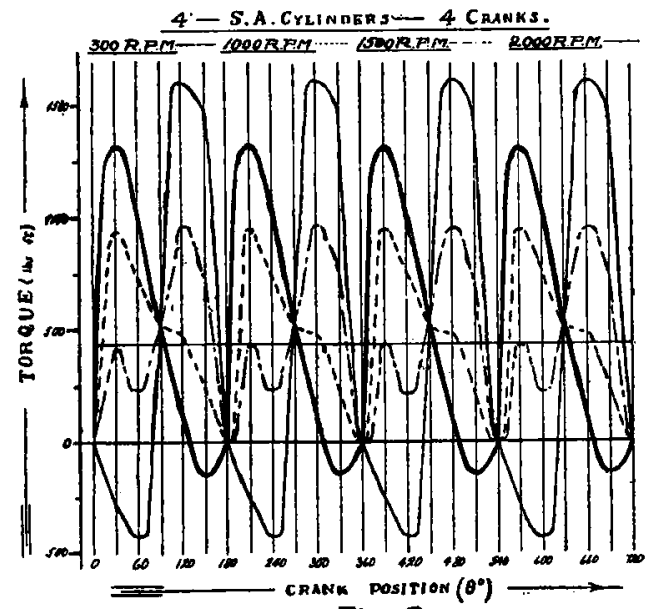

Fig. 9

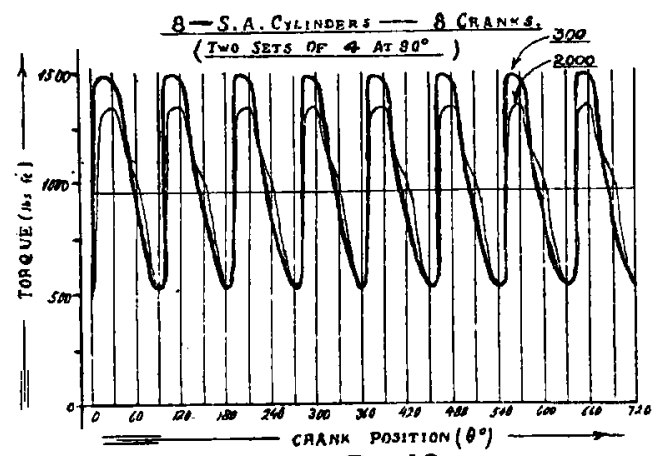

Fig. 10 


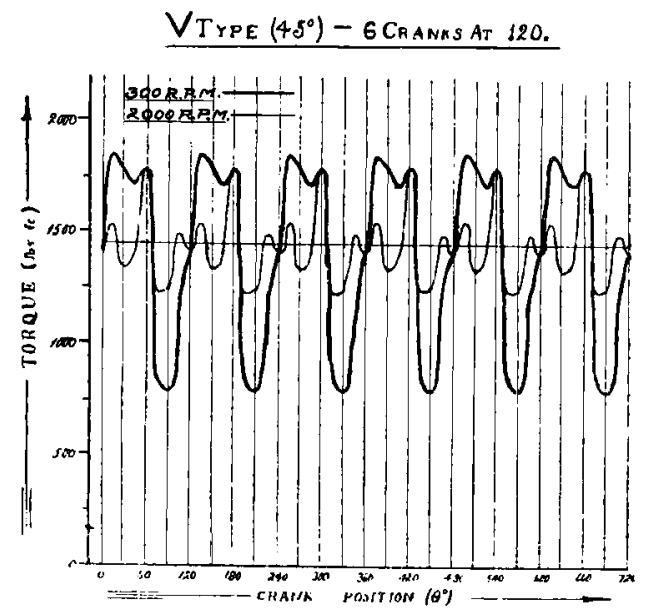

Fig. 21 


\section{THE DISCUSSION.}

Prof. Scroles, in opening the discussion, disagreed with the author in regand to the balancing of the Fullagar and Doxford opposed-piston engines. He pointed out that oven if the upper and lower reciprocating masses in each cylinder were equal there would still be different inertia forces due to the different piston accelerations, caused in the case of the Fullagar engine by one piston being driven by a crank on the inner dead centre, and the other by a crank on the outer dead centre, while the connecting rod lengths varied in the Doxford engine. He also questioned the author's statement that the Diesel engine would be at a disadvantage as compared with the high-compression engine, on the ground that the author had only allowed a mean effective pressure of $100 \mathrm{lb}$. per sq. in. on the Diesel engine as against $125 \mathrm{lb}$. per sq. in. for the other. He pointed out that Mr. Hawkes had published experimental work in which he had obtained a mean effective pressure of about $150 \mathrm{lb}$. per sq. in. from a Diesel engine.

Mr. W. D. Williamson pointed out that for speeds between 2,000 and 3,000 revs. per minute, with pistons of ordinary design, the peak of the inertia load would be higher than the peak of the load due to gas pressure, as actually proved by the fact that the inner side of the crank pin was often worn more than the side upon which the pressure of the explosion fell. He also expressed a doubt in regard to the high torque shown at high speeds, in view of the fact that, in practice, the maximum torque was usually obtained between about 900 and 1,600 revs. per minute, falling away after the latter speed owing to the decrease in the volumetric efficiency of the engine.

Mr. GEo. W. WATSON pointed out that a two-cylinder engine with cranks together had many good points, in that it was extremely simple, it required only one cam to operate the inlet and exhaust valves and gave very uniform torque, and owing to the fewness of parts could be made very cheaply. He also confirmed Prof. Scholes' remarks in regard to the relative value of the inertia force and the explosion force at speeds of 3,000 revs. per minute.

Mr. KerSEY, in replying on the discussion, agreed with the speakers in regard to the relative value of the inertia force and the explosion pressure. He also agreed with Prof. Scholes with regard to the want of balance in the Fullager engine, but stated that he was referring only to the first period vibration, and corrected his statement to read that the Fullagar engine was balanced as well as a four-cylinder four-crank engine.

In reply to Prof. Scholes, he pointed out that the high mean effective pressure of $150 \mathrm{lb}$. per sq. in. could only be obtained in a Diesel engine by increasing the maximum pressure, and therefore the maximum temperature. 